\title{
USP Escuela de enfermería y el Programa de Inclusión Social: un enfoque histórico
}

\section{USP School of Nursing and Social Inclusion Program - A Historical Approach}

\section{A Escola de Enfermagem da USP e o Programa de Inclusão Social - Uma abordagem histórica}

\section{Rayana Pereira Dias ${ }^{1}$, Genival Fernandes de Freitas² y Bárbara Barrionuevo Bonini³}

${ }^{1}$ Acadêmica na Escola de Enfermagem da Universidade de São Paulo. Correo electrónico: rayana.dias@usp.br

${ }^{2}$ Professor Doutor Titular na Escola de Enfermagem da Universidade de São Paulo. Correo electrónico: genivalf@usp.br

${ }^{3}$ Doutora em Ciências em University of Oulu. Correo electrónico: bonini@usp.br

Cómo citar este artículo en edición digital: Dias, R. P., Freitas, G. F. y Bonini, B. B. (2020). USP Escuela de enfermería y el Programa de Inclusión Social: un enfoque histórico. Cultura de los Cuidados

(Edición digital), 24 (56) Recuperado de http://dx.doi.org/10.14198/cuid.2020.56.08

Correspondencia: Av. Dr. Enéas Carvalho de Aguiar, 419 - Cerqueira César, São Paulo - SP, 05403-000 - Brasil.

Correo electrónico de contacto: Rayana.dias@usp.br

Recibido:29/11/2019

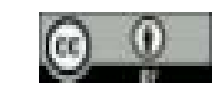

Aceptado:13/01/2020:

\section{ABSTRACT}

In the early days of Brazilian nursing, the best category to build the profession was sought: white women. The color of one skin was an impediment to study nursing. At the Nursing School of University of São Paulo (EEUSP), there was never an official mechanism to bar black people from taking the course, but even so, it has always trained a small number of black students. With USP's Social Inclusion Program (Inclusp), in 2007, the expectation was to expand access to the University for this particular group of people. That is why, this study was based on the hypothesis that few black nurses graduate EEUSP still, compared to the white majority who enter the course each year. Goals: Identify whether EEUSP continues to train few black nurses, even with affirmative action, and describe the experience of black and brown school students and alumni. Method: First, it sought to map how many benefited from the program and who these people were; then, some of these black graduates were invited to tell their stories and experiences as a student. Results: The color underreporting in the studied documentation compromised the results. There were five descriptive 
interviews. Conclusions: That despite the program, EEUSP continues to train few black nurses, contributing to the fact that, until today, the number of black nurses trained by public institutions remain small.

Keywords: Affirmative action, blacks, nursing, history of nursing.

\section{RESUMEN}

En los primordios la enfermería brasileña, se buscó la mejor categoría para desarrollar la profesión: las mujeres blancas. El color de la piel era un impedimento para hacer enfermería. En la Escuela de Enfermería de la USP (EEUSP), nunca ha habido un mecanismo oficial para impedir que las personas negras hacen el curso, pero aun así, siempre ha capacitado a pocos estudiantes negros. Con el Programa de Inclusión Social (Inclusp) de USP, en 2007, la expectativa era ampliar el acceso a la Universidad para este grupo específico. Por lo tanto, el presente estudio asumió que EEUSP continúa formando pocos negros, en comparación con la mayoría blanca que ingresa al curso cada año. Objetivos: Identificar si EEUSP continúa capacitando a pocas enfermeras negras incluso con acciones afirmativas y describir la experiencia de estudiantes y ex alumnos negros y marrones dentro de la escuela. Método: Primero, buscó mapear cuántos se beneficiaron y quiénes eran estas personas; Luego, algunos de estos graduados negros fueron invitados a contar sus historias y experiencias como estudiantes. Resultados: El subregistro de color en la documentación estudiada comprometió los resultados. Hubo cinco entrevistas descriptivas. Conclusiones: concluyó que a pesar del programa, EEUSP continúa formando pocos negros, lo que contribuye al hecho de que, hasta hoy, el número de enfermeras negras capacitadas por instituciones públicas es pequeño.

Palabras clave: Políticas afirmativas, negros, enfermeira, historia de enfermería.

\section{RESUMO}

Nos primórdios da enfermagem brasileira, buscou-se a melhor categoria para construir a profissão: mulheres brancas. A cor da pele era um impedimento para cursar enfermagem. Na Escola de Enfermagem da
USP (EEUSP), nunca houve um mecanismo oficial para barrar pessoas negras de fazer 0 curso, mas mesmo assim sempre formou poucos alunos negros. Com o Programa de Inclusão Social da USP (Inclusp), em 2007, a expectativa era de que se ampliasse 0 acesso à Universidade para esse grupo específico. Desta forma, o presente estudo partiu do pressuposto que a EEUSP continua a formar poucos negros, comparativamente à maioria branca que ingressa no curso a cada ano. Objetivos: Identificar se a EEUSP continua formando poucos enfermeiros negros mesmo com ações afirmativas e descrever a experiência de alunos e exalunos pretos e pardos dentro da Escola. Método: Primeiro, buscou-se mapear quantos foram beneficiados e quem eram essas pessoas; em seguida, alguns esses egressos negros foram convidados a contar sua história e suas vivências como aluno. Resultados: A subnotificação de cor na documentação estudada comprometeu os resultados. Foram feitas cinco entrevistas descritivas. Conclusões: Apesar do programa, a EEUSP continua formando poucos negros, contribuindo para que, até hoje, o número de enfermeiros negros formados por instituições públicas seja diminuto.

Palavras chave: Ações afirmativas, negros, enfermagem, história da enfermagem.

\section{INTRODUÇÃO}

A fundação das primeiras escolas de enfermagem Nightingaleanas do Brasil, Anna Nery e Escola de Enfermagem da USP, ocorreu entre as décadas de 1920 e 1940 - respectivamente, épocas em que a abolição da escravidão ainda era um fato relativamente recente. $\mathrm{O}$ ser negro era tido como inferior, algo que ficava claro nas regras impostas para o ingresso de alunas que, uma vez formadas, iriam construir a enfermagem no Brasil (Campos, 2012). Especialmente na Anna Nery, onde os 
Revista científica de la Asociación de Historia y Antropología de los Cuidados (Universidad de Alicante)

mecanismos de barragem eram oficiais (Barreira, 1997).

Passaram-se 128 anos apenas que a escravidão foi abolida oficialmente do país. E os resquícios do racismo não deixaram de existir, impactando de forma ampla na vida da população negra, que majoritariamente constitui esse país. Por exemplo, 70\% das camadas mais desfavorecidas da população são constituídas por negros (Nery e Costa, 2009); em 2017 brancos ganhavam 72,5\% mais que pretos ou pardos (IBGE, 2018). Se têm poucos recursos financeiros e constituem a camada de base que sustenta o sistema capitalista no qual o Brasil está inserido é óbvio que essa população terá menos acesso à educação, saúde, emprego e moradia do que o restante dos brasileiros (Leite, 2011)

No fim dos anos 90 e durante a primeira década dos anos 2000 houve grande movimento geral acerca de ações afirmativas nas universidades brasileiras. Esse processo culminou na aprovação da Lei 12.711/2012, popularmente conhecida como Lei de Cotas que instituiu a reserva de $50 \%$ das vagas das universidades federais para alunos de escola pública além da reserva do número correspondente de pretos, pardos e indígenas de cada estado. Na Universidade de São Paulo, foi implantado um programa de bonificação a partir do ano de 2007, o Inclusp que previa uma bonificação para alunos de escola pública, não implicando a reserva de vagas.
Um estudo mostrou que de todos os formados na Escola de Enfermagem da Universidade de São Paulo, desde sua fundação até o ano de 2006 aproximadamente 3\% eram não brancos (Bonini, 2010). Será que mesmo com o Inclusp a Escola de Enfermagem continua formando poucos negros e negras? Como já dito anteriormente, a Universidade de São Paulo adotou um sistema de bonificação como ação afirmativa em 2007. Mas é importante destacar que o Programa só passou a ter a opção de bônus para autodeclarados pretos, pardos e indígenas em 2014. O programa de inclusão da Universidade vigorou até 2018, com a adesão das cotas.

Tendo em vista esse panorama geral, este artigo tem como objetivo identificar o número de alunos negros matriculados na Escola de Enfermagem da USP, no período de 2007 a 2017, que foram beneficiados pela pelo Programa de Inclusão Social da USP e descrever a experiência universitária dos mesmos.

\section{MATERIAL E MÉTODO}

Trata-se de um estudo históricosocial, desenvolvido em duas etapas. $\mathrm{Na}$ primeira, foram analisadas as fichas de admissão dos alunos ingressantes na Escola de Enfermagem da Universidade de São Paulo, nos anos de 2007 a 2017, que se encontram sob a guarda do Serviço de Graduação da referida Escola. Junto da análise das fichas de admissão, também 
foram consultadas as listas de alunos beneficiados pelo INCLUSP e a lista de alunos graduados no período de 2010 a 2016. A partir desses dados foi feita uma triagem com todos os alunos e ex-alunos para identificar os que se autodeclaravam pretos ou pardos e convidá-los à entrevista para explorar as experiências que eles tiveram.

As entrevistas foram realizadas utilizando um questionário semiestruturado, em local e data de escolha do participante, que foi elucidado e assinou o Termo de Consentimento Livre e Esclarecido. Para ter acesso aos dados quantitativos e entrevistar a população alvo, o presente estudo foi submetido ao Comitê de Ética em Pesquisa da Escola de Enfermagem da USP em maio de 2017 (CAEE: 68745417.2.0000.5392).

\section{RESULTADOS E DISCUSSÃO}

Dentre os resultados quantitativos, destacam-se os seguintes aspectos:

- 239 alunos entraram pelo Programa, no total, nos dez anos estudados;

- Infelizmente, nos registros não havia informação da autodeclaração de cor dos ingressantes de antes de 2014 (ano em que a universidade passou a ter bônus específico para pretos, pardos e indígenas), e mesmo depois: apenas os alunos que entraram por esta modalidade tinham documento de autodeclaração assinado. Deste modo é difícil saber se esse grupo sócio racial adentrou de fato a

Universidade;

- $12 \%$ (28,6 prontuários) representa o grupo PPI - mas devese ressaltar novamente que esse dado foi subnotificado;

- $7 \%$ dos ingressantes entraram com mais de 25 anos,

- $13,7 \%$ desses ingressantes desistiram do curso.

O percentual de ingressantes com mais de 25 anos demonstra a relação de classe social com a idade de ingresso no ensino superior: a tendência é de que quanto mais desfavorecidos socialmente, menor o acesso à educação e mais tempo para passar no vestibular (Piotto, 2008; 2011).

Foram realizadas cinco entrevistas no período de dezembro/2018 à maio/2019 que tiveram como objetivo explorar as experiências por aqueles que as vivenciaram e seguindo o método proposto, foram criadas três categorias temáticas, que por mais distintas que sejam, estão intrinsecamente entrelaçadas. São elas: Experiências além da vida acadêmica; Experiências como alunos de graduação; Impressões após a vida acadêmica.

\section{Experiências além da vida acadêmica}

Nesta categoria, são inseridos os relatos sobre a autodeclaração étnica das entrevistadas e os desdobramentos dessa questão. Em todos os depoimentos o conflito de cor surgiu, bem como a complexidade do assunto. O relato do "se descobrir negro" compõe o processo de formação de 
Revista científica de la Asociación de Historia y Antropología de los Cuidados (Universidad de Alicante)

identidade dessas pessoas e, segundo algumas das entrevistadas, é um processo infinito de questionamento e aceitação da própria condição uma vez que ser negro no Brasil tem um peso, viver esta realidade tem uma carga marcada por preconceitos e estigmas.

Partindo deste ponto: sob a ótica da identidade racial dos entrevistados, a maioria descreve o quanto essa questão é ou já foi muito delicada para eles; o real significado de dizer que se é negro e colocarse numa posição de vulnerabilidade perante a sociedade, tendo em vista a coisificação do povo preto e os movimentos eugenistas ao longo da história do Brasil (Pinto e Ferreira, 2014). O olhar sobre si mesmo ao declararse preto ou branco reflete imediatamente na percepção geral de tudo que acontece ao seu redor; sendo ele o protagonista ou não.

A negação da cor é um fenômeno comum entre os relatos, bem como suas repercussões que variam desde a vã tentativa de mudar algo que é imutável (a cor da pele) à adoção dos inúmeros eufemismos para não declarar-se preto. O primeiro é descrito de forma impactante por um dos entrevistados ao relatar um acontecimento de sua infância:

"Quando eu tomava banho eu tentava... Passar bastante sabão para ficar Menos preto ou... Que meu cabelo ficasse liso. [...] Uma vez eu tentei colocar sabão no olho para o olho ficar claro.” (Entrevistado 5)
Que sofrimento era esse capaz de fazer com uma criança tentasse tornar sua pele clara e apagar seus traços com sabão? No mínimo, essa criança era associada à sujeira apenas pela cor de sua pele e textura de seu cabelo. Levando em consideração esse relato, é possível dizer que a cor da pele não interfere em nada na vida de uma pessoa? Que reconhecer-se negro e assumirse como tal perante os outros é algo fácil e comum?

O mesmo vale para os eufemismos que são utilizados pela população brasileira desde o primeiro censo do IBGE. Morena clara; morena; café com leite; chocolate são alguns exemplos de autodeclaração de cor, para não assumir-se negro. Esta é a prova prática do colorismo no Brasil. As pessoas têm dificuldade de reconhecer a própria cor devido à inferiorização dos negros desde a era colonial e os movimentos eugenistas da primeira república (Pinto e Ferreira, 2014). É uma peculiaridade do Brasil os cinquenta tons de preto? Os relatos colhidos sobre isso nas entrevistas eram praticamente iguais: negação da cor até reconhecerem que os tais cinquenta tons de preto podem ser diferentes, mas todos eles são preto.

\section{Experiências como alunos de graduação.}

Nesta segunda categoria entram os sentimentos e vivências ocorridos durante a graduação. Foram trazidos relatos de situações de racismo ocorridas com os entrevistados, problemas e receios próprios 
da graduação e até mesmo experiências em que a universidade serviu como uma ferramenta de autoconhecimento e autoafirmação.

As vivências como alunos negros dentro da Escola de Enfermagem e logicamente, a auto percepção da cor interfere diretamente na forma como essas pessoas enxergam o mundo e lidam com ele. Como enxergaram e lidaram com as situações de racismo foram os relatos mais marcantes. Uma das entrevistadas contou que um paciente recusou sua assistência pelo fato de ela ser negra. Depois de contar o fato ela disse que não passou por situações “tensas” relacionadas à sua cor. Ou seja, será que ela não considerou esse fato de sua vida como racismo? Ou será que ela não consegue identificar as dimensões do racismo velado em seu cotidiano? Essa mesma entrevistada afirmou que não sabia se o racismo não a afetava ou se ela é quem não notava, pois o tom de sua pele era claro.

Esse é o clássico ponto de intersecção entre a negação da cor e a realidade. Para a realidade todos os tons de preto, são preto. (Ferreira, 2002)

Ainda nessa temática, outra entrevistada perguntou o que era considerado racismo. Ela tinha dúvidas se era preta ou parda e se incomodava muito com isso. Ela contou que as colegas de turma diziam que ela ia mal em clínica e em saúde do adulto porque era do Centro Acadêmico. A entrevistada questionou se isso era racismo. Essa situação é parecida com a anterior: nesta a ex-aluna não sabia identificar o que é racismo e na antecedente a entrevistada não sabia avaliar a gravidade do ato. Mas de novo, para entender e identificar racismo primeiro é preciso perceber como as relações se dão quando se destaca a própria cor e a dos demais indivíduos ao redor. (Ferreira e Camargo, 2011).

$\mathrm{Na}$ mesma categoria apareceu de forma gritante o subtema da representatividade. Ou a falta dela. Dos cinco entrevistados, quatro expressaram sua indignação por não se sentirem representados na Escola de Enfermagem; na Universidade de São Paulo e dentro da própria profissão. Contaram nunca ter tido professores ou enfermeiras negras nos campos de estágio. Enfermeiras alguns até viram, no mesmo campo e não mais que duas vezes. Olhar em volta e não ver ninguém parecido levantou neles o questionamento de onde estavam os pretos na enfermagem e se estariam na enfermagem, já que é tão raro vê-los.

“Normalmente eu só via pessoas negras quando voltava no final de semana pra casa.” (Entrevistado 5)

Esta frase denota o quanto a ausência de pretos era gritante e o quanto ele mesmo era algo que parecia não pertencer socialmente aquele lugar.

\section{Impressões após a vida acadêmica}


Revista científica de la Asociación de Historia y Antropología de los Cuidados (Universidad de Alicante)

A questão da representatividade se

desdobra para a terceira a última categoria: impressões após a graduação, onde se torna o foco principal. Justamente por não terem convivido com enfermeiras negras durante a graduação, a maioria dos depoimentos demonstrava a preocupação de não serem contratados por conta da cor da pele. Que é um raciocínio totalmente lógico. Principalmente ao observar os dados de identificação sócio econômica da profissão levantados pelo Conselho Federal de Enfermagem - Cofen: no estado de São Paulo, 70\% das enfermeiras são brancas; 18,9\% pardas e 5,6\% pretas (Cofen, 2013).

Os entrevistados verbalizaram também a certeza de que iriam sofrer algum grau de racismo no trabalho ou mesmo procurando por um. Destaca-se aqui o uso da palavra grau: existem graus de racismo? Um grau mais leve é aceitável enquanto que um grau mais pesado não? Se existem graus de racismo, em que eles se baseiam? Nos vários tons de preto que permeiam a sociedade brasileira?

E mais uma vez tem-se o colorismo protagonista dos processos de vida dos entrevistados. A relação deles com a própria cor é o elo que liga as três categorias.

Ao relacionar os principais dados quantitativos com os resultados qualitativos é possível visualizar grande parte do primeiro refletido no segundo.

A subnotificação do dado cor nos registros quantitativos foi extremamente marcante, apresentando um número baixíssimo de ingressantes pretos ou pardos, que se materializou nas vivências dos entrevistados como falta de representatividade.

Com relação à cor, não se identificavam entre os alunos; entre as docentes; e nem entre as enfermeiras. Isso foi trazido repetidas vezes por quatro dos cinco entrevistados. Seguindo essa lógica pode-se inferir que sim: no período estudado poucos alunos negros adentraram a escola de Enfermagem da USP e o conteúdo das entrevistas confirma isso. Simultaneamente a esse raciocínio tem-se que: se o próprio dado era subnotificado; o número de ingressantes pretos e pardos pode ter sido bem maior porque entraram usando outros tipos de bônus, ao passo que, tendo sido posta a questão do colorismo, não se assumindo como tal esses alunos passaram despercebidos ou invisibizados em relação aos outros. É uma hipótese.

A maioria deles relatou um percurso de no mínimo, três anos para adentrar a Universidade. Apenas dois chegaram a entrar com mais de vinte e cinco anos, mas quase todos tiveram um espaço de tempo entre a conclusão do ensino médio e o ingresso no superior. Tempo de tentativas. Refletindo a tendência das pessoas menos favorecidas para ingressar no ensino superior. (Piotto, 2008)

A Universidade fez a autoanálise de todo o Inclusp e outras medidas de ampliação do acesso, que foi publicada pelo Jornal da USP, numa edição especial em 
2016. No especial tem-se claro que a adesão de cotas era a última opção considerada pela Universidade como ação afirmativa; que a constante mudança do Inclusp se devia a sua insuficiência e que o foco da universidade sempre foi ampliar o acesso numa perspectiva econômica e não de diversidade étnica, ou justiça social. Segundo o então pró-reitor de graduação, Antônio Carlos Hernandes, a ação afirmativa social seria suficiente para ampliar 0 acesso a universidade, pois além de pobres, pretos e indígenas estariam incluídos dentro dessa realidade.

Em 2015, a Universidade criou uma nova porta de entrada utilizando o Enem visando melhorar seus resultados de inclusão. Em 2017, o Conselho Universitário aprovou finalmente as cotas raciais, depois de esgotar todos os recursos para atingir sua própria meta de inclusão: 50\% dos alunos de graduação egressos de escola pública (Teixeira, 2018).

Apesar da análise da USP ser positiva em relação ao Inclusp, depoimentos de alunos ingressos pelo programa também publicados no especial, demonstram que mesmo com a bonificação, tiveram trajetórias acadêmicas longas e um deles critica a ausência das cotas raciais; além de artigos na mesma linha de pensamento.

\section{CONCLUSÃO}

O Programa de Inclusão Social da USP, de forma geral foi bem avaliado pela Universidade contradizendo as inúmeras modificações para corrigir suas deficiências.
E que apesar de ter como objetivo a inclusão, o programa nunca foi pensado como justiça social ou reparação histórica, talvez por isso os dados de raça/cor dos ingressantes não foram colhidos. A Universidade tinha uma meta: até 2018, 50\% dos alunos de graduação deveriam ser oriundos de escola pública. O prazo para alcance da meta foi modificado para 2021. Ao longo dos anos o Programa se mostrou insuficiente e atualmente, extinto.

Tendo em vista esses fatos e o cruzamento dos dados e das entrevistas, conclui-se que a Escola de Enfermagem da USP continua formando poucos negros. Inclusive no quadro docente, que em sua maioria é de enfermeiras formadas pela Escola. É interessante visualizar como essa questão identitária perpassa o meio estudantil, profissional e acadêmico.

Quando a enfermagem foi implantada no Brasil pela Missão Parsons, o mecanismo de barrar a entrada de negros era oficial. Vê-se que na atualidade, as barreiras são outras. Ou será que são as mesmas? Que barreiras são essas, afinal? E, por que razão ver uma enfermeira negra é raridade?

\section{REFERÊNCIAS}

Barreira, I.A. (1997). Os primórdios da Enfermagem Moderna no Brasil. Escola Anna Nery Revista de enfermagem. 1 (esp),161-76.

Campos, P.F.S. (2012). História social da enfermagem brasileira: afrodescendentes e formação profissional pós-1930. Revista de 
Revista científica de la Asociación de Historia y Antropología de los Cuidados (Universidad de Alicante)

Enfermagem Referencia. serIII(6), 167177.

Nery M.P. e Costa L.F. (2009). Política afirmativa racial: polêmicas e processos de identidade do cotista universitário. Psico-USF. 14(2), 211-20.

Leite, J.L.(2011). Políticas de cotas no Brasil: política social? Rev. Kat. 14(1):23-31.

Bonini, B.B. (2010). Ser enfermeiro negro na perspectiva da transculturalidade do cuidado. (Tese de mestrado não publicada). Escola de Enfermagem, Universidade de São Paulo: São Paulo.

Piotto, D.C. (2011). Estudantes das camadas populares no ensino superior público: qual a contribuição da escola? Psicologia Escolar e Educacional. 15(1), 81-9.

Piotto, D.C. (2008). Trajetórias Escolares Prolongadas nas Camadas Populares. Cadernos de Pesquisa. 38(135), 701-27.

Minayo, M.C.S. (2014). O Desafio do Conhecimento - Pesquisa qualitativa em saúde. São Paulo: Hucitec.

Petruccelli, J.L., Saboia, A.L. (2013) Estudos e Análises. Informações

demográficas e socioeconômica. Características étnico-raciais da população - classificações e identidades. Rio de Janeiro: Instituto Brasileiro deGeografia e Estatística. Recuperado de https://biblioteca.ibge.gov.br/visualiza cao/livros/liv63405.pdf
Conselho Federal de Enfermagem. (2015). Perfil da enfermagem no Brasil. Recuperado de http://www.cofen.gov.br/perfilenfermag em/bloco1/tabelas/sudeste/sp/Enfermeir os.pdf .

Ferreira, R.F. (2002). O brasileiro, o racismo silencioso e a emancipação do afrodescendente. Psicologia \& Sociedade. 14(1), 69-86.

Ferreira, R.F. e Camargo A.C. (2011). As relações cotidianas e a construção da identidade negra. Psicologia: Ciência e Profissão. 31(2), 374-389.

Pinto, M.C.C. e Ferreira, R.F. (2014). Relações raciais no Brasil e a construção da identidade da pessoa negra. Revista Pesquisa e Práticas Psicossociais. 9(2), 257-266.

Ferreira, R. A. (05 de janeiro de 2018). O sistema de cotas étnico-raciais adotado pela USP. Jornal da USP.

Instituto Brasileiro de Geografia e Estatística. (05 de dezembro de 2018). Síntese de Indicadores Sociais: indicadores apontam aumento da pobreza entre 2016 e 2017. Agencia Notícias IBGE.

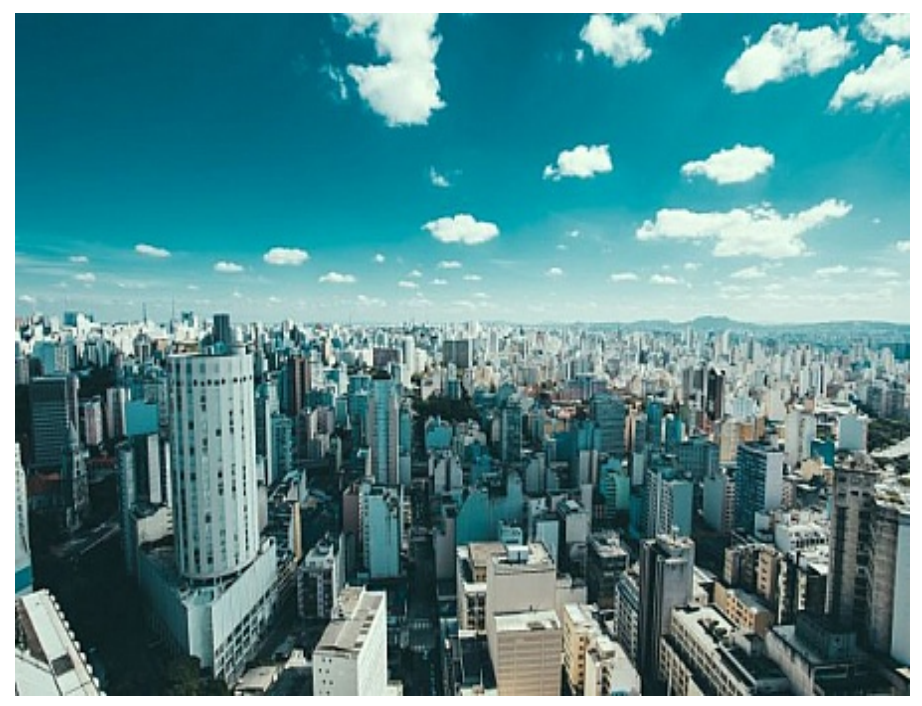

Fuente: https://freerangestock.com/search/all/sao-paulo- 